\title{
USING VIRTUAL ENVIRONMENTS TO SUPPORT ELECTRICAL SAFETY AWARENESS IN CONSTRUCTION
}

\author{
Dong Zhao \\ Jason Lucas \\ Walid Thabet \\ Dept. of Building Construction \\ Virginia Tech \\ Blacksburg, VA 24061, USA
}

\begin{abstract}
Safety is important to the construction industry. Every year lives are lost due to accidents that could have been prevented with proper training and awareness of workplace hazards. Electrical safety hazards are the cause of about a quarter of all deaths within the construction industry. Enhanced training methods that are active and interactive can augment electrical safety training for all construction workers and reduce accidents and fatalities caused by electrical shock. Virtual Environment (VE's) simulations have been used with success for safety training within the construction industry. VE simulation offers an active form of training that allows the user to interact with a modeled environment. This active training allows for a development of cognitive abilities and awareness that typically improve the users' comprehension of training material. This paper discusses issues concerning electrical safety within the construction industry. It then discusses the benefits of using an active training approach such as VE simulation and its effects on the cognitive abilities of users. Lastly, a proposed safety training program is discussed that can help augment electrical safety training practices in the construction industry. Within the proposed safety training program a VE simulation prototype is planned. The initial development of the prototype simulation is also presented.
\end{abstract}

\section{INTRODUCTION}

Electricity exists as a hazardous condition to the workers within the working environment of any construction project. It is present in the form of overhead and underground power lines, temporary and permanent power supplies, temporary lighting, hand tools, and wiring. No matter what the source or form of electricity, it exists as a hazard to those who work around it. Each year construction workers are injured or killed due to electrical related accidents. It is important that all construction workers are aware of electrical hazards that they may encounter and the proper preventative actions to reduce the chance of electrical shock.

\subsection{Electrical Hazards}

Electrical shock occurs when the human body comes in direct contact with an electrical current or in contact with a piece of machinery or a tool that is in direct contact with an electrical current and the electrical current follows the body as a path to ground. The severity of the shock is dependent upon the amount of current that flows through the body, the path the current takes through the body, and the length of time the body serves as the circuit. The current's voltage, presence of moisture in the environment, phase of the heart cycle when the shock occurs, and the general health of the person prior to the shock occurrence are also factors of shock severity. Effects to the body can range from barely perceptible to severe burns or immediate cardiac arrest (OSHA 2009a).

Between 1992 and 1999 electrocution was the fifth leading cause of all occupational fatalities in the United States and the cause of 1,144 electrocutions in the construction industry. The construction trades account for 39\% of all occupational related electrocution fatalities and have the second highest fatality rate out of all occupations (Taylor et al. 2002). Between 2003 and 2006, electrocution was listed as the cause of 488 deaths in the construction industry by the U.S. Department of Labor's Bureau of Labor Statistics (2009). In a separate study, Janick (2008) noted only 26\% of the construction fatalities listed as electrocutions were connected to electricians, meaning that the majority of the electrocutions occur to non-electrical workers. In that same study, it was noted that $10 \%$ of all construction industry deaths in 2006 were electrocution related. 
In a separate study (Dong et al. 2007) of data from the U.S. Bureau of Labor Statistics, electrocution was ranked as the fourth leading cause of death in construction in 2005. The top three leading causes were falls to a lower level, transportation injuries, and struck-by objects and equipment. Although electrocutions caused $9 \%$ of the 1,243 construction-worker deaths, electrical shock accounted for less than $1 \%$ of reported recordable nonfatal injuries in 2005. Most accidents involving electricity and electrical shock cause severe injury or death

From the same study (Dong et al. 2007), it was noted that the construction occupations having the highest average electrocutions per year were electricians, construction laborers, supervisors/managers, and electrical power installers and repairers. The causes of electrocutions in construction differ between electrical workers and non-electrical workers. Between 2003 and 2005, the main cause of electrocution of electrical workers (electricians, electrical power installers and repairers, their apprentices and helpers doing electrical work, and their supervisors) was contact with energized, or "live", equipment and wiring. The secondary cause of electrical workers' deaths was contact with overhead power lines (Figure 1a). The main cause of electrocution of non-electrical workers was contact with overhead power lines and the secondary cause was by machinery and appliances with faulty electrical systems (Figure 1b). Contact with overhead lines includes direct contact by the person (accounting for about $20 \%$ of overhead line contract) and indirect contact such as equipment or material transferring the current and causing electrocution (accounting for $80 \%$ of overhead line contact accidents).
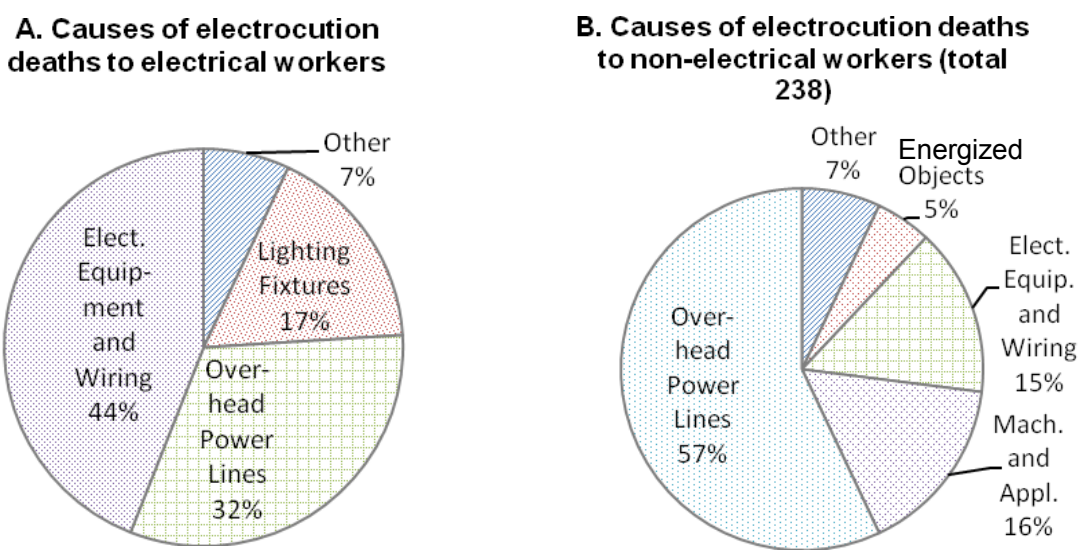

Figure 1: Electrocution deaths in construction between 2003 and 2005 (data from Dong et al. 2007).

Different types of electrical injuries that occur include electrical shocks, electrical burns, heat burns, arc blast effects (hearing loss and physical injuries), and falls as a result of electrical shock. Between 2003 and 2005, electrical shock was listed as the cause of 362 deaths. Arc flashes or blasts were responsible for 11 deaths (Dong et al. 2007).

\subsection{Fatality Case Studies}

NIOSH investigates fatal occupation injuries through its Fatality Assessment and Control Evaluation (FACE) Program. Deaths from electrocutions are one of the FACE Program's target areas (NIOSH 2009). FACE reports are publically available through NIOSH online <http:/ / www.cdc.gov/ niosh/face/>. The FACE reports are used to show examples of different types of electrical shock and electrocution accidents that happened in real life. FACE \#2003-10 \& \#1993-10 serve as examples of contact with overhead power lines. FACE \#1993-10 and \#1994-17 are poor examples of administering aid and first response. FACE \#1994-17 also serves as an example of how contacting wires. FACE \#1991-05 is an example of ensuring use of cords with proper insulation and an accident resulting because of contact with live wiring. FACE \#1990-22 shows what can happen when proper lock-out and tag-out procedures are not followed and what happens when equipment is not deenergized before working on it. FACE \#1988-02 is an example of electrocution through faulty light fixture wiring.

The FACE report summaries show that electrical safety is a concern to everyone on site and each worker needs to be aware of the possible hazards that exist within their working area. Two common suggestions of NIOSH, within several of the FACE reports, to prevent similar occurrences on the job are to "conduct a jobsite survey during the planning phases of any construction project to identify potential hazards, and to develop and implement appropriate control measures for these hazards" and to "develop, implement and enforce a comprehensive safety and health training program in language(s) and literacy level(s) for workers, which include training in hazard recognition and the avoidance of unsafe conditions."

Hazard awareness training is important to the goal of reducing electrical related accidents. A Virtual Environment (VE) simulation based safety training program is proposed. A VE simulation based safety training program can offer an engaging 


\section{Lucas, Zhao and Thabet}

and interactive tool for training all construction workers on electrical hazards and safe working procedures. This paper investigates current safety training requirements and practices within the construction industry related to electrical safety. The benefits of using VE simulation and its enhancement of cognitive learning abilities are also explored. The proposed safety training program that uses VE simulations for hazard awareness and procedural training, the VE prototype development, and early implementation is also discussed.

\section{CURRENT INDUSTRY TRAINING}

The Occupational Safety and Health Administration (OSHA) sets forth requirements for training of all workers that work around or with electricity. They also have requirements of training for construction workers. The fulfillment of those requirements is the responsibility of each individual employer. Some employers use structured safety programs and materials developed by media companies that specialize in training while others conduct their own training. The important part of any training program is that it meets the minimum requirements set forth by OSHA and that the developed training program adequately trains each employee so they can safely perform their tasks on the jobsite.

\subsection{OSHA Requirements}

OSHA's Code of Federal Regulations (CFR) Part 1926 Subpart K covers electrical safety and health regulations for the construction industry. The requirements found in CFR 1926 Subpart K as well as referenced standards 1910.333 and 1910.334 are designed to offer an understanding to workers of the relevant safety practices to use and hazards that exist while working on or near electrical equipment or electrical distribution systems.

CFR 29 Part 1910.332 (OSHA 2009c) requires training for all employees who may be expected to face risk of injury due to electric shock or other electrical hazards. The training should allow each worker to gain an understanding of safety-related working practices around electricity. This includes training for workers who are not working directly on electrical equipment but who are required to work in close proximity to electrical equipment and electrical distribution systems. These individuals are responsible for identifying hazards that exist within the work environment and the proper corresponding practices. The OSHA regulations cover areas of regulations for protection of the employees, exposed energized equipment near passageways and open spaces that may put other workers at risk, and working with cords and cables including those attached to electrical hand tools. Within these regulations are procedures for de-energizing equipment, tagging equipment, identifying environment ware on equipment, use of temporary electrical equipment, and batteries and battery charging.

OSHA regulations are meant to form the minimum requirement of what to include in an electrical safety program. To ensure up-to-date information on electrical safety, employers, professional organizations, and OSHA recommend further compliance with two consensus standards. Those standards are the National Electrical Code (NFPA 70) and the Standard for Electrical Safety in the Workplace (NFPA 70E). NFPA 70 deals with design and installation of electrical equipment while NFPA 70E deals with working on electrical equipment (Kolak 2007).

\subsection{Industry Practices}

Multiple construction company safety training programs were examined to determine how electrical safety training fits within their company safety plans and project specific safety plans. General contractors typically approach electrical safety practices for their workforce as part of the overall training orientation for new hires and within their overall company safety program. Some companies require new workers to participate in an OSHA 30 Hour Outreach Training program for general safety training and used the electrical module of that training class to inform their employees of general electrical safety and hazard awareness. Site specific electrical hazards are often covered at weekly meetings at each site or during daily hazard meetings.

During the safety meetings and orientations different materials are used for the training of employees that include slide shows, videos, books, and other hand outs. Within these materials regulations are presented for safe working procedures and equipment usage. The construction industry also takes advantage of using case examples of fatality assessments such as the NIOSH FACE reports or within the mechanical industry MCA Toolbox Talks. These methods take advantage of describing a scenario and an action that caused an accident or fatality. They also discuss the lessons learned and the proper procedures that should have been followed to prevent the accidents and properly follow regulations. In this method of training a real life aspect is brought into the training in an "it can happen to you" scenario and allows the trainees to relate conditions and regulations with real life situations and a life or death importance.

Safety professionals emphasize the importance of proper extension cord use, ensuring that cords and power tools have the proper ground, and the use of GFCIs on the worksite when training general employees. Site superintendants are trained on temporary power and lighting issues to ensure their employees as well as subcontractors and subcontractor employees are properly installing and working with temporary electricity. Depending on the size of the job and company the superintendant 


\section{Lucas, Zhao and Thabet}

or a designated safety professional is ultimately responsible for enforcing the company's safety regulations including the regulations for using temporary power, electrical tools, and cords.

When the superintendent is in charge of all safety including electrical issues on site there are several barriers that make enforcing electrical regulations difficult. These include the knowledge level of the superintendent. It is difficult for one individual to be aware of all the regulations of every task that goes on during a site. In terms of electrical safety this is difficult because electricians work on different types of equipment and power sources. The voltage of each equipment determine protective clothing and procedural practices involved in completing each task. The superintendant typically does not know this information so the company takes steps to insure that they are informed and can adequately enforce regulations. Another barrier for general contractors is insuring that only qualified persons are working on electrical distribution systems. Nonelectrical works who install low voltage systems such as alarms and communications are at risk when they connect their systems to a main electrical distribution panel or working on a live system. This leads to a risk of electrical shock if they do not take proper procedures or have a qualified electrician perform the task.

Electrical safety is a concern on site to make sure everyone that is working on site is following proper procedures and is informed of existing hazards. Each company has developed programs to train individuals of electrical hazards and safety. Individuals within these training programs are trained with books, videos, slideshows, weekly meetings, and classroom based sessions. These methods of learning are passive in nature. Passive methods of training are not engaging and may not maximize knowledge acquisition and retention, especially for more complex tasks (Burke et al. 2006). Adult learners have been identified as 'problem-centered' and 'solution-driven' (Kowalski and Vaught 2002) so training methods that are more engaging and task-centered are likely to be more effective for adults and lead to better comprehension of materials.

\section{IMPROVING TRAINING THROUGH VIRTUAL ENVIRONMENT SIMULATION}

Since the passive methods of learning that are currently used are not the most effective for adult learners and comprehension levels are often higher with active and interactive training, it is believed that an active and interactive training program would be more effective for the industry. Neville (1998) suggests that effective training programs can help save large costs by preventing accidents. Effective training does not only save lives with fewer accidents but eliminates the extra indirect costs associated with accident investigations, insurance rates, equipment downtime and repair, lost productivity, and finding replacement help. Safety programs may have a cost associated with their creation but a safe working environment with fewer accidents decrease insurance rates, increase productivity, and better quality work by extending the cost savings to clients and getting more work by completing it at a lower cost (McKinnon 2000).

There are several ways to make learning more active and engaging. Classroom-based learning is more active with discussions, group brainstorming, and participant involvement (Bonwell and Eison 1991) as opposed to passive learning of listening to an instructor lecturing. These active learning techniques in a classroom only offer a certain level of interactivity. Other training methods like on-the-job training, full scale training mock-ups, and the use of Virtual Environment (VE) simulation offer more engagement. VEs are often used in place of on-the-job training or full size simulation because the technology allows for safe simulation of real-life events in a digital environment that might otherwise be too dangerous or expensive to create (Haller et al. 1999). VEs also have the ability to create a problem-based learning exercise in an environment that replicates the trainee's actual working environment (McAlpine and Stothard 2003). A VE is described as a 3-dimensional world seen from a first-person point of view that is under real-time control of the user (Bowman et al. 2005). A training program that uses a VE offers an interactive, active, and cognitive learning experience for the user (Stanney and Zyda 2002; Munro et al. 2002). Because of the level of safety VEs allow and the level of danger associated with working around electricity, the use of VE for an electrical safety training is proposed.

\subsection{Past uses of VE}

VEs have been used with varied success for fire-fighter training (Querrec and Chevaillier 2001), mine safety training (Lucas et al. 2008), security in refineries (Haller et al. 1999), buildings' fire detection systems (Bukowsky and Sequin 1997), safe equipment operation (Hollands et al. 2000) and shipboard fire fighting (Tate and Sibert 1997).

Specifically within the construction industry VEs and VR technology have been used for constructability analysis of precast concrete (Soemardi 2000), structural analysis application development (Setareh, et al. 2005), as well as for safety training and simulation. Irizarry and Abraham (2005) have explored the use of VR in improving safety in steel erection through the use of an immersive environment. It allows for the simulation and recognition of hazards during steel erection without the actualization of the danger. VE has also been used to simulate working on scaffolding in hopes to reduce the risk of falling once the workers enter the real worksite (Hsiao et al. 2005). 


\section{Lucas, Zhao and Thabet}

VE has been used as a simulation and training tool for electricians and electrical work. Sulbaran and Shiratuddin (2006) proposed a framework for developing a VE tool for electrical design and installation review for designers and electrical contractors. A tool that would help with coordinating systems, lead to a reduction in rework, and ultimately save all parties money. Immersive VE has also been used for training of lineman to work on live line cutout switches through the use of a head mounted display and glove system. The program trains the user of proper procedures for completing this very dangerous work (Park et al. 2006). No known projects deal with the use of VEs in electrical safety training in terms of general construction needs and situations.

\subsection{Learning with VE}

Using VE's for training offers enhancement of cognitive learning, learning by active participation, increased motivation, and flexibility in terms of time and location. Cognitive learning is a process of acquiring knowledge and understanding through thought, experience, and the senses (Driscoll 1994). When tasks are more cognitively demanding than physically demanding those tasks are called cognitive tasks. To enhance human performance of cognitive tasks, an understanding of how information is processed is needed. Wickens (1992) describes the human information-processing model. In this model, information is perceived by sensors and held-up in a temporary memory. It is then acted upon through dedicated actuators and stored into long-term memory. The long-term memory stores practiced work methods or algorithms for future use. At the same time, information is captured by the various sensory systems. Each of the sensory systems has a short-tem memory where stimuli remain, even for a short time after they are gone. The memory perceives the stimuli and processes them. The stimuli are then recognized, indentified, or classified into long term memory where they are recalled for later response to other stimuli based on past experiences.

The way that VEs work with theories of cognitive learning is that they allow training through rehearsal of tasks and experience of consequences in a close to real-life familiarity (Stothard et al. 2004). The interaction within a VE cause perceptual, memory, and decision making cognitive processes that lead to an understanding of location knowledge, structural knowledge, behavior knowledge, and procedural knowledge that can then be transferred to the real working environment (Munro et al. 2002). Adults can cognitively focus on a few things at a time. When outside distractions take cognitive resources to handle, it is taking those resources away from other aspects of the job, like safety. Through simulation and repetitive practice of safe processes through meaningful interaction, safety can become ingrained as second nature and not require as high of a cognitive load (Trybus 2008). Studies have been completed that conclude the brain reacts in similar ways in both the virtual and real environment which suggests a transfer of knowledge between simulated activities and real world activities (Mikropoulos 2001). Through repetitive simulation, processes become second nature to people as part of their muscle memory and their reactions become automatic (Stefanidis et al. 2008).

Eschenbrenner et al. (2008) summarize benefits of learning within a 3D environment. Those benefits include the ability for students to experiment without concern for "real-world repercussions" and the ability to "learn by doing." With a VE program, the user controls the objects and couples this with information and descriptions and later task-based testing, thus, an interactive and active-learning experience is created.

Another important characteristic of the personal computer VE-based programs is the flexibility (in terms of time and location) that they offer to the user. In traditional classroom-based training/instruction, availability of the training provider and trainees need to be coordinated to schedule the training session. VEs, especially when designed for use with a personal computer, allow for convenience of location and time. The user can participate in the training in a job trailer, office, or conceivably the back of a truck with a laptop computer. There is no limitation to classroom or training schedules. Tracking the user performance can be built into the applications, which reduces the need for direct trainee observation.

\section{TRAINING PROGRAM STRUCTURE}

A VE simulation based training program is proposed to enhance electrical safety awareness within the construction industry. This program includes training points that meet OSHA requirements and refers to current industry practices for electrical training. All training content are arranged into categories and integrated into a series of scenarios that are designed around accident case studies, industry suggestions about common hazards, and FACE reports.

\subsection{Training Elements Matrix}

A review of literature and industry training practices was conducted. This allowed for the development of a list of training points that need to be incorporated into an electrical safety training program. To structure the training program, all the training points are arranged into the training elements matrix (Figure 2). 


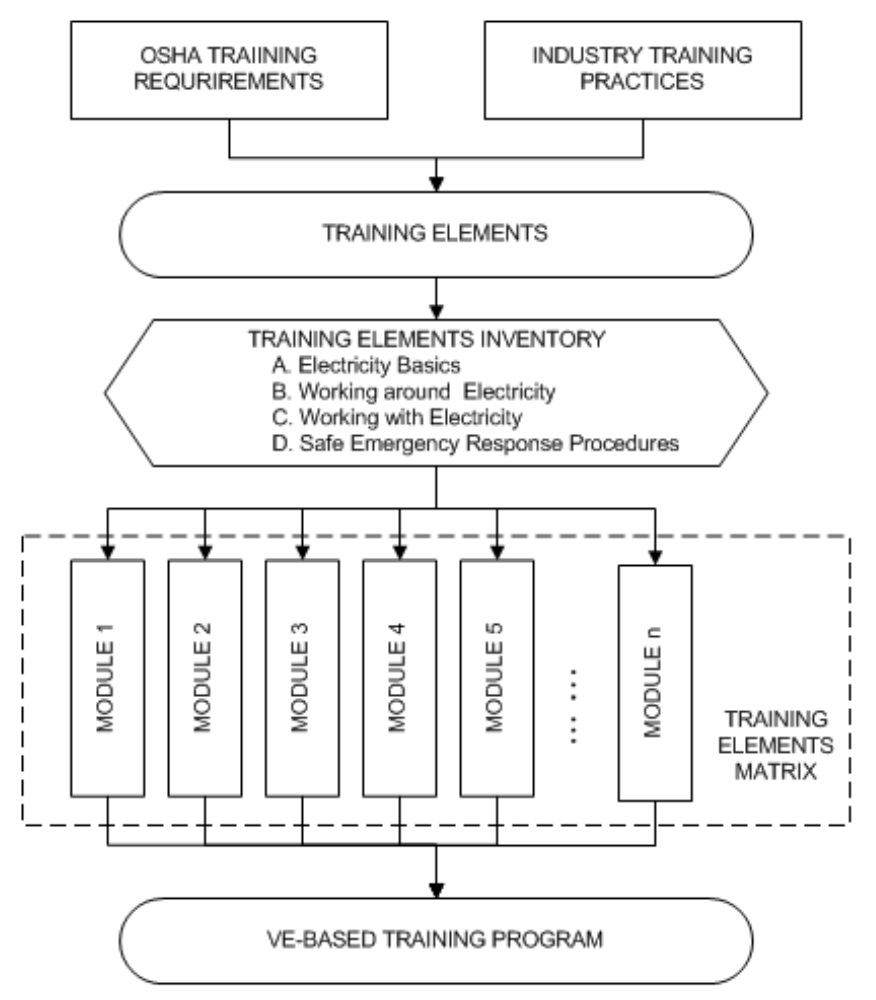

Figure 2: Electrical training program structuring.

Training elements were extracted from OSHA regulations for work around electricity and suggestions received from industry members, other literature review. Each element is a training objective that the trainee must complete. Each training element is then categorized into the Training Elements Inventory. This inventory consists of four training categories: (1) Electricity Basics which includes electricity fundamentals such as current flow and shock sources; (2) Working around Electricity which deals with safety regulations for working around electrical power sources and what precautions that need to be taken; (3) Working with Electricity, which includes topics of proper use of temporary power, extension cords, electric tools, personal protective equipment, and identifying equipment decay and environmental deterioration; and (4) Safe Emergency Response Procedures which includes proper response procedures to use when attempting to administer aid to someone who comes in contact with an electrical hazard.

The categorized training elements are then incorporated into a series of modules relating to specific hazards that make up the Training Elements Matrix. The matrix consists of two axes (Figure 3), the Hazard Category Axis and the Category Axis. All the training elements that refined from the previously collected information in the training elements inventory are filtered into this matrix, and then stored for further simulation. Each hazard module is design on information retrieved from fatality cases in FACE reports, information presented in MCA Toolbox Talks, and industry suggestions that deal with electrocutions in construction. Each module represents a major hazard and can cause electrocution. The working conditions that workers are exposed to related to each hazard are simulated with the module. The VE simulations allow the user to be exposed to the hazards within the simulated environment so they can recognize those hazards and proper working procedures and transfer their experiences to real life environments. The Training Elements Matrix is expandable to add more scenarios of different hazards. 
Lucas, Zhao and Thabet

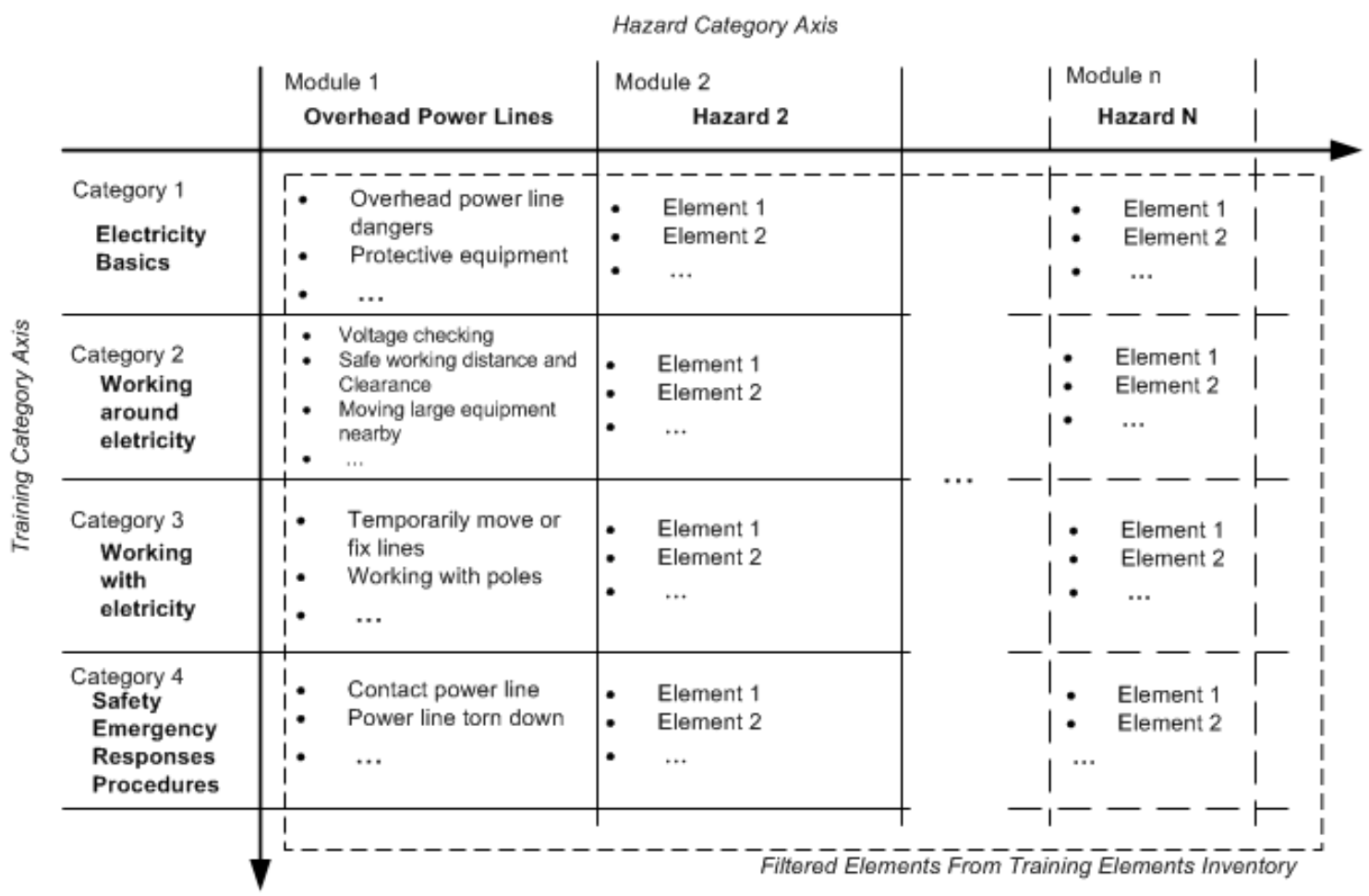

Figure 3: Training Elements Matrix.

Contact with overhead power lines is the largest cause of fatalities to non-electrical construction workers and the second largest cause of fatalities to electrical workers. Overhead power line safety is the hazard category for module 1 . The training elements for each of the training categories dealing with this hazard were extracted from OSHA safety requirements and recent FACE reports dealing with overhead power line accidents.

In order to design the overhead power line module the Training Elements Inventory is filtered for all relevant training elements that fall into each training category. The basics of working around overhead power lines, the dangers that put the worker and risk, and proper protective equipment that should be used are examples of the training elements stored in category 1 for the overhead power line hazard module. Voltage checking, safe working distances and clearances, moving of large equipment near power lines are training elements in category 2, working around the electricity. In category 3 , temporarily moving or fixing power lines, working with poles are examples of training elements. Category 4 deals with rapid response for administering aid/assistance when contacting power lines or when power lines are torn down. How to response rapidly and correctly when contacting power lines or when power lines torn down are the training elements in category 4.

\subsection{Example Training Scenario}

When the training elements matrix is completed, each hazard module consists of a series of scenarios. Each scenario is simulated independently. This allows the user to choose which scenarios they would like to complete. This allows the user to complete specific training relevant to their working task or work environment (see Figure 4).

The model components for each scenario are created in AutoDesk's 3D Studio Max. The completed models were then imported into GarageGames' Torque 3D game engine where the digital virtual environment is compiled. The interactive events and corresponding animations are controlled by programming scripts in Torque 3D using $\mathrm{C}++$ syntax.

Each training element is programmed as an independent interactive event. These events are triggered by various approaches depending on the desired reaction. For examples, a touch approach is used to trigger the training event for safety emergency responses on "contact power line" when the user touches a power line. Another example would be when arriving in the area of a torn-down power line, a proximity approach triggers the event dealing with broken power lines emergency. These events are a mixture of animations and text used to present material to the user. All presenting methods used in the scenario are aimed at increasing the learning efficiency and enhancing the training effectiveness. The learning efficiency and training effectiveness will be studied through evaluation processes discussed in future research. 


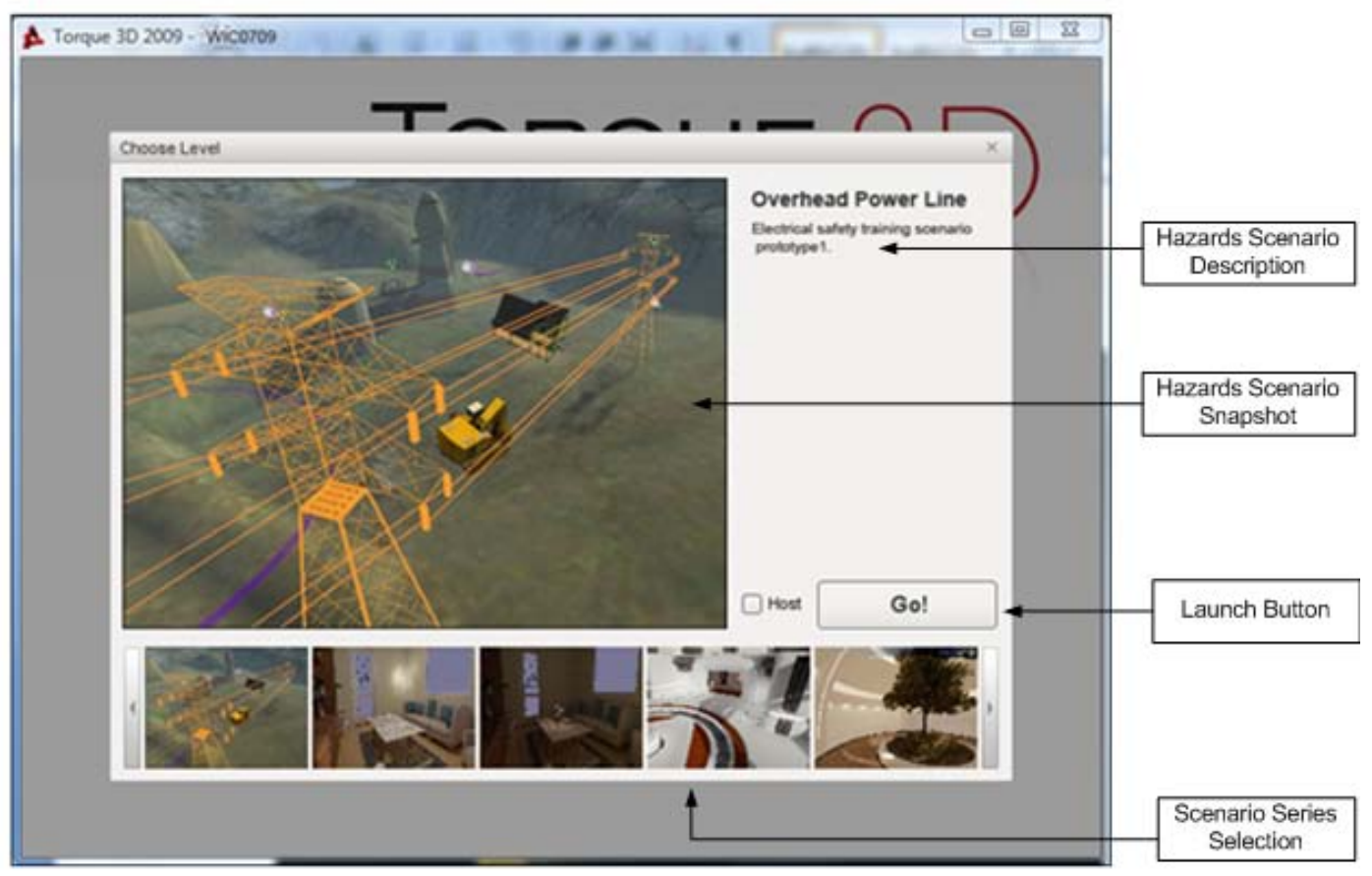

Figure 4: Screenshot on scenario series selection.

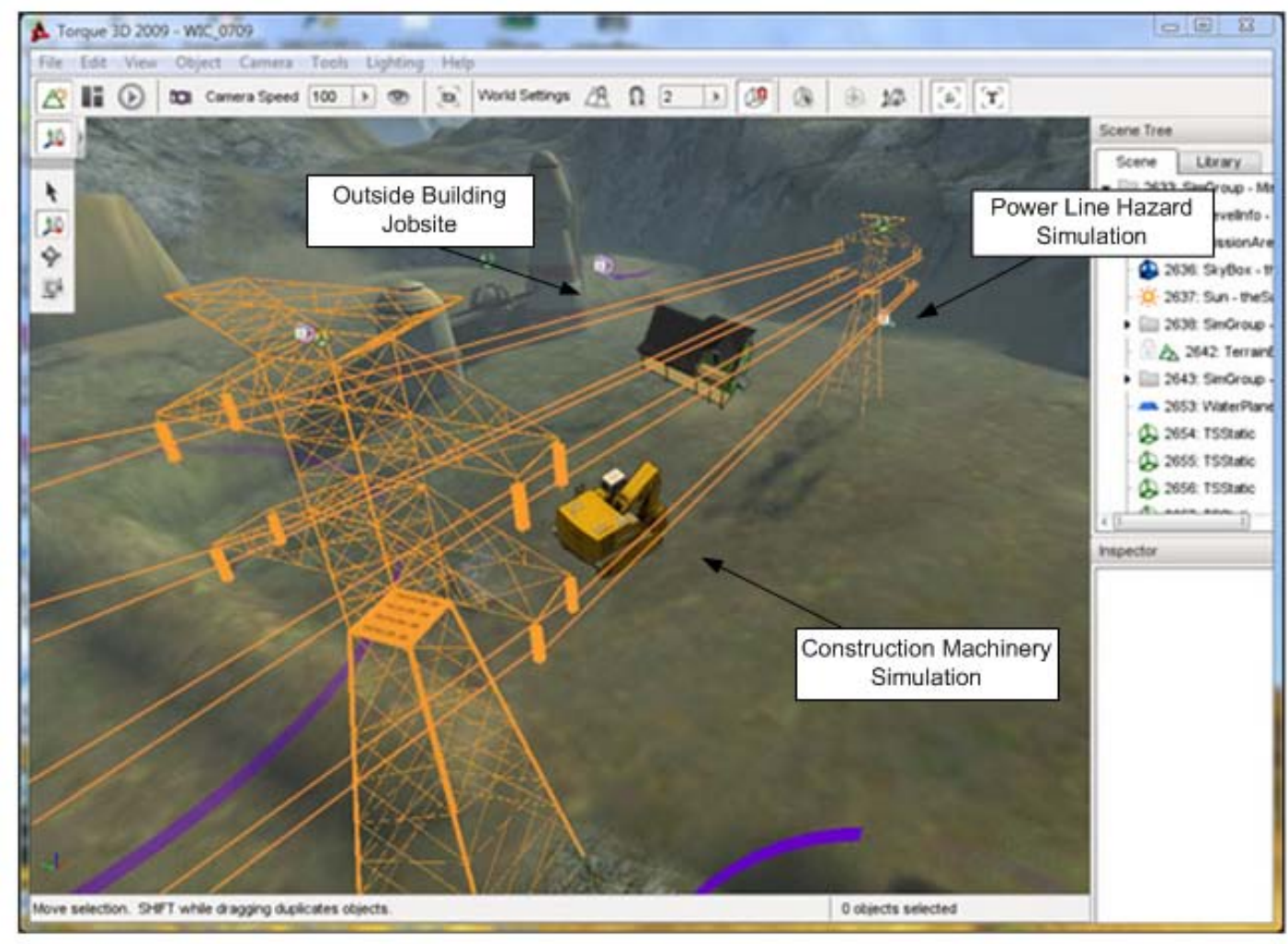

Figure 5: Overview of overhead power line hazard simulation in the design interface. 
The designed prototype scenario uses an overhead power line as an environmental hazard. The simulation is set in an outside environment. There is a building on the site in close proximity to an overhead power line. A simulated piece of construction machinery is also included for training purposes (Figure 5). In this scenario, the user has free navigational control of the environment in either first-person or third-person view. The view switching function is intended to avoid dead angles or prevent the user from being stuck in an area of the 3D environment. At the same time the view switching provides the user with a more engaged visual feeling and allows them to explore situations from multiple angles for a better spatial understanding. While the user is walking through the scenario various triggers are touched causing the game engine to respond with the programmed reactions. For example, when the user walks close to the 10 -foot distance line indicating the distance from the overhead power lines' upright projection allowed by safety regulations, the training element of "safe working distance and clearance" is triggered and a text panel appears on the screen explaining this safety regulation (see Figure 6). Clues are used throughout the scenario to attract the user and lead them to finish all interactive training events and view all simulations within the scenario. For example, a warning sign is set near a high voltage power tower. A flashing light on the sign is the clue drawing the user to approach and read it. When the user stops at the sign, the information of training element "voltage checking" shows up near that sign explaining the importance of understanding the voltage of the line when working in close proximity to the line. Learning occurs unconsciously and impresses the trainee in a positive manner through these training simulations. In addition, the triggers are repeatable so that the reactions may be repeated to reinforce the training elements.

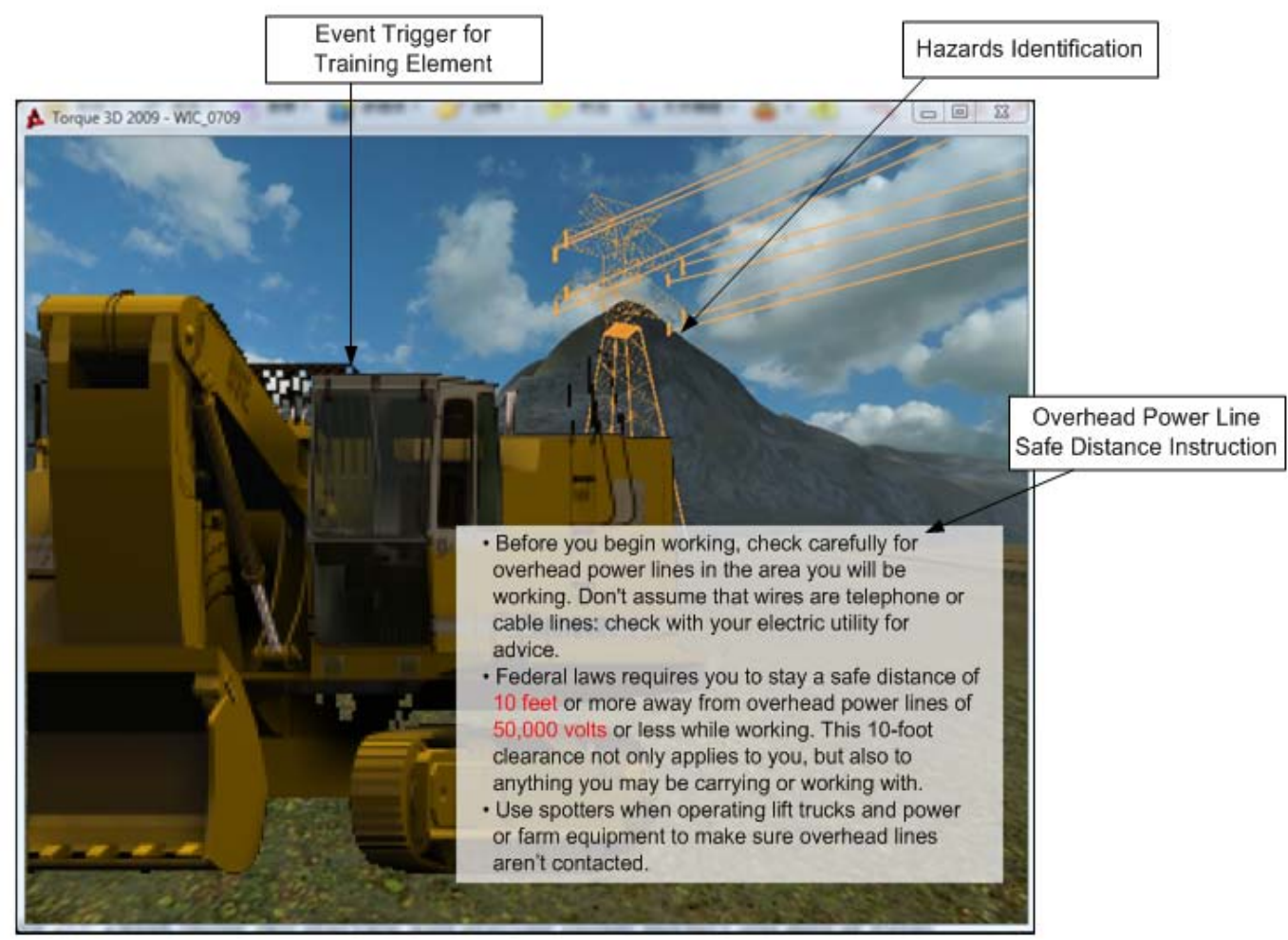

Figure 6: Training example in overhead power line hazard module

At the completion of the hazard scenario the user will complete a connected task-based training scenario. This task-based training section will contain most of the same triggers as in the training section but the reaction will change. For example, if the user walks to close to the power line, no instruction will be given, but an electric arc will take place reducing the user's health points for failure to take proper safety precautions. At the test beginning, the user are given 100 health points, if they do something correctly according the training matrix, their health points will increase, otherwise their health points will drop until reaching 0 which indicates test failure. The number of health points reduced represents the severity of the infraction. The more likely a failure is to cause electrocution and death, the higher number of health points will be removed.

\section{PROGRAM DEVELOPMENT OVERVIEW}

The Training Elements Matrix and module simulations fall within an overall training program that consists of six steps (figure 7). Information gathering and analysis (step 1) was first completed to gain a basic understanding of industry needs and 
training practices. Then that information was organized into the Training Elements Matrix (step 2). With the Training Elements Matrix developed, the training elements are then simulated for the training prototype (step 3). The prototype development consists of several scenarios designed to teach and test the user of proper working procedures within the overhead power lines hazard module.

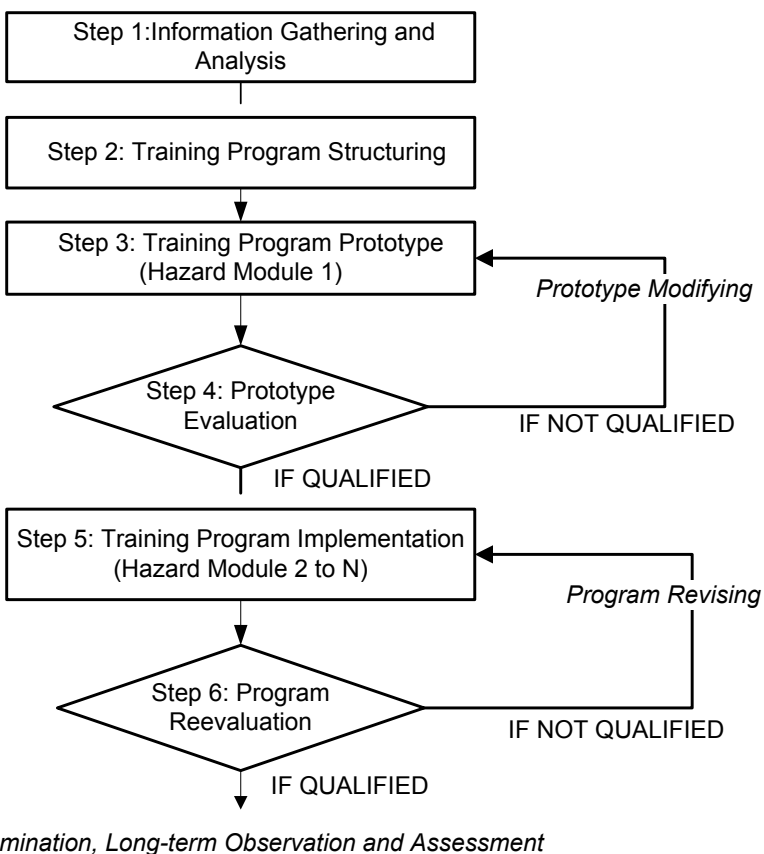

Figure 7: Training Program development flowchart.

After completing the piloting prototype and confirming its functionality, it will go through industry evaluation (step 4). Collected feedback will be used for prototype modification in terms of usability and information rationality. The feedback of industry evaluation will help to modify the ease of navigation and environmental interaction, completeness of training points, and the understandability of information. The prototype will go through several rounds of evaluation and refinement. Once these rounds of evaluation on the prototype are complete, the other hazard modules will be designed and implemented (step 5). The complete training program will then be evaluated by the industry (step 6). The information presented in the new modules will be evaluated by the industry. The entire program will then be evaluated with a focus on its usefulness and effectiveness.

\section{DISCUSSION}

Evaluation of the prototype, especially in terms of interface design and user interaction within the environment, is very important to the success of the training program. Once when the interface design is understandable and the user interactions easy to understand and perform the application will be available for an effectiveness study. To get the prototype to a point that will allow for effectiveness studies requires industry participation and real trainee (targeted user group) feedback. In the future, long term behavioral observation and economic efficiency studies can be performed.

One issue with the development of a safety training application that allows for complete training of electrical safety through VE simulation is that many hazards are task or environmental based. Not every employee would need to be familiar with every hazard or environment. The VE training program will allow for selecting specific tasks and working environments to customize worker training to their needs. This will allow for training on relevant tasks and materials and prevent an overload of information to the user, most of which he or she may not come in contact with. The modules developed within the Training Element Matrix allow for this sorting of relevant hazard training and scenarios. Another benefit to the module organization is that new elements can be added for specific companies and not all training scenarios need to be developed at once. Scenarios can be selected and filtered within a system based upon the training points that the user needs to learn in order to safety complete their assigned tasks in the real environments. 


\section{Lucas, Zhao and Thabet}

It is the goal of this research that a developed training program that utilizes the VE simulation for training and testing workers within the construction industry can help to cut down on accidents and fatalities related to electrical shock and electrocution. If adequate evaluation of the program is performed during and after development such a program can allow for the creation of a safer working environment and help protect the safety of workers with in the construction industry.

\section{REFERENCES}

Bonwell, C., and J. Eison. 1991. Active Learning: Creating Excitement in the Classroom. In ERIC Digest. ERIC ID: ED340272, ERIC Clearinghouse on High Education Washington DC.

Bowman, D.A., E. Kruijff, J.J. Jr. LaViola and I. Poupyrev. 2005. 3D User Interfaces: Theory and Practice, p 512. Boston: Pearson Education.

Bukowsky R, and C. Sequin C. 1997. Interactive Simulation of Fire in Virtual Building Environments. In Proceedings of the 24th Annual Conference on Computer Graphics and Interactive Techniques, Los Angeles, California, 35-44.

Bureau of Labor Statistics (BLS). 2009. Occupational Injuries/Illness and Fatal Injuries Profiles <http://data.bls.gov/GQT/servlet/IntialPage> [accessed February 4, 2009]

Burke, M.J., S.A. Sarpy, K. Smith-Crowe, S. Chan-Serafin, R.O. Salvador, and G. Islam. 2006. Relative effectiveness of worker safety and health training methods. American Journal of Public Health, 96(2):315-325.

Dong, X., Y. Men, A. Fujimoto, J.Gittleman, M. McCann, C. Trahan, and L. Welch. 2008. The Construction Chart Book: The U.S. Construction Industry and its Workers. $4^{\text {th }}$ Ed. Silver Spring, MD: The Center for Construction Research and Training.

Driscoll, M.P. 1994. Psychology of Learning for Instruction. Massachusetts: Allyn and Bacon.

Eschenbrenner, B., F. Fui-Hoon Nah, and K. Siau. 2008. 3-D Virtual Worlds in Education: Applications, Benefits, Issues, and Opportunities. Journal of Database Management, 19(4): 91-110.

Haller, M., G. Kurka, J. Volkert, and R. Wagner. 1999. omVR - A Safety Training System for a Virtual Refinery. In Proceedings of ISMCR '99, Workshop of Virtual Reality and Advanced Human-Robot Systems, Tokyo, Japan, 10: $291-298$.

Hollands, R. et.al. 2000. Equipment Operation and Safety Training using Virtual Reality and SAFE-VR. In Minesafe International 2000. Perth, WA.

Hsiao, H., P. Simeonov, B. Dotson, D. Ammons, T. Kau and S. Chiou. 2005. Human responses to augmented virtual scaffolding models. Ergonomics, 48(10):1223-1242.

Irizarry, J., and D. Abraham. 2005. Application of Virtual Reality Technology for the Improvement of Safety in the Steel Erection Process. In Proceedings of the 2005 ASCE International Conference on Computing in Civil Engineering, Cancun, Mexico.

Janick, C. A. 2008. Occupational Fatalities due to Electrocutions in the Construction Industry. Journal of Safety Research, 39: 617-621.

Kolak, J. 2007. Electrical Safety: Elements of an effective program. Professional Safety. 52(2):18-24.

Kowalski, K.M. and C. Vaught. 2002. Principles of adult learning: Application for mine trainers. In Strategies for Improving Miners' Training, R. Peters, ed. Publication no 2002-156, Information Circular 9463; 3-8 September 2002 (US Department of Health and Human Services, Public Health Service, Centers for Disease Control and Prevention, National Institute for Occupational Safety and Health, DHHS (NIOSH)).

Lucas, J., R. McMahan, R. Engle, D. Bowman, W. Thabet, S. Scafrik, and M. Karmis. 2008. Improving Health and Safety through Conveyor System Training in a Virtual Environment. In Proceedings International Future Mining Conference, Nov. 19-21, 2008. Sydney, Australia.

McAlpine, I. and P.M. Stothard. 2003. Using multimedia technologies to support PBL for a course in 3D modeling for mining engineers. In Proceedings of ED-MEDIA 2003 World Conf. on Ed. Multimedia, Hypermedia and Telecommunications. Honolulu, Hawaii, 24-28 June 2003, p2449-2455.

McKinnon, R. 2000. Cause, Effect, and Control of Accident Loss. CRC Press. Boca Raton, FL; Taylor \& Francis Group.

Mikropoulos, T. 2001. Brain Activity on Navigation in Virtual Environments. Journal of Educational Computing Research, 24(1): 1-12.

Munro, A., R. Breaux, J. Patrey, and B. Sheldon. 2002. Cognitive Aspects of Virtual Environments Design”, in Handbook of Virtual Environments: Design, Implementation, and Applications. Ed. Stanney, K., Mahwah, New Jersey : Lawrence Erlbaum Associates, publishers. pg. 415-434.

Neville, H. 1998. Workplace Accidents: They cost more than you might think. Industrial Management. 1(40):7-9.

Occupational Safety and Health Administration (OSHA). 2009a. OSHA Construction eTool: Electrical Incidents. <http://osha.gov/SLTC/etools/construction/electrical_incidents/mainpage.html> [accessed June 4, 2009] 
Occupational Safety and Health Administration (OSHA). 2009b. Regulations (Standards - 29 CFR) Definitions to this subpart. -1910.399 .

<http://www.osha.gov/pls/oshaweb/owadisp.show_document?p_table=STANDARDS\&p_id=997 $6>$ [accessed February 12, 2009]

Occupational Safety and Health Administration (OSHA). 2009c. Regulations (Standards -29 CFR). <http://www.osha.gov/pls/oshaweb/owasrch.search form?p doc type=STANDARDS\&p toc I evel=1\&p_keyvalue=1910> [accessed February 12, 2009]

Park, C., G. Jang and C. Young-Ho. 2006. Development of A Virtual Reality Training System for Live-Line Workers. International Journal of Human Computer Interaction 20(3): 285-303.

Setareh, M., D. Bowman, and A. Kalita. 2005. Development of a Virtual Reality Structural Analysis System. Journal of Architectural Engineering, 11(4):156-164.

Soemardi, B. 2000. VR for Precast Concrete Constructability Analysis. Computing in Civil Engineering, Proceedings of the Eight International Conference on Computing in Civil and Building Engineering, August 14-16, Stanford, CA, USA. Pg 302-308.

Stanney, K., and M. Zyda. 2002. Virtual Environments in the 21st Century, Handbook of Virtual Environments: Design, Implementation, and Applications. Ed. Stanney, K., Mahwah, New Jersey: Lawrence Erlbaum Associates, publishers. pg. 114.

Stefanidis, D., M. Scerbo, C. Sechrist, A. Mostafavi, and B. Heniford. 2008. Do novices display automaticity during simulator training? The American Journal of Surgery, 195: 210-213.

Stothard, P.M., J.M. Galbin, and J.C.W. Fowler J.C.W. 2004. Development, Demonstration, and Implementation of a Virtual Reality Simulation Capability for Coal Mining Operations. Proceedings ICCR Conference, Beijing, China.

Sulbaran, T. and M.F. Shiratuddin. 2006. A Proposed Framework for a Virtual Reality Training Tool for Design and Installation of Electrical Systems. 6th International Conference of Construction on Construction Applications of Virtual Reality, CONVR 2006, Orlando, Fl. Aug. 3-4.

Tate, D.L. and L. Sibert. 1997. Virtual Environments for Shipboard Firefighting Training. Proceedings of 1997 Virtual Reality Annual International Symposium (VRAIS '97). 61.

Taylor, A.J., G. McGwin Jr., F. Valent, L.W. Rue III. 2002. Fatal Occupational Electrocutions in the United States. In Injury Prevention. 8(2002); 306-312.

Trybus, J. 2008. Making Safety Second Nature. Professional Safety, 53(12):54-55.

Querrec, R. and P. Chevaillier. 2001. Virtual Storytelling for Training: An Application to Fire Fighting in Industrial Environment. Proceedings of the International Conference on Virtual Storytelling: Using Virtual Reality Technologies for Storytelling (September 27-28, 2001). O. Balet, G. Subsol, and P. Torguet, Ed. Lecture Notes in Computer Science, vol. Springer-Verlag, London, 201-204.

Wickens, C. 1992. Engineering Psychology and Human Performance, New York, New York: Harpers Collins.

\section{AUTHOR BIOGRAPHIES}

DONG ZHAO is a Ph.D. candidate and graduate research assistant in the Department of Building Construction at Virginia Tech. His research interest includes simulation and visualization for safety training as well as visualization technologies for project planning. He has received his Master in Management Science and Engineering (Construction Management) and his Bachelor's degree in Construction Engineering and Management from Chongqing University, Chongqing, China. His email is $<$ dongzevt. edu $>$.

JASON LUCAS is a Ph.D. candidate and graduate research assistant in the Department of Building Construction at Virginia Tech. His research interests include using virtual reality for safety training and using Building Information Modeling technologies for information tracking and processing. He has received his Bachelor's of Architecture degree from New Jersey Institute of Technology and his Master of Science for Building Construction Science/Management from Virginia Tech. His email is $<j$ lucas 06 evt. edu>.

WALID THABET is a Professor and Head of the Department of Building Construction at Virginia Tech. His research interests include using information technologies for construction means and methods, planning and scheduling, preliminary and detailed cost estimating, temporary excavation support, formwork systems, and unconventional construction techniques. His email address is <thabetevt.edu>. 